\title{
Ácidos graxos e composição centesimal da carne de coelhos alimentados com ração contendo farelo de coco
}

\author{
Fatty acid profile and proximal composition of meat from rabbits fed diets containing coconut meal
}

Daniela Vieira de SOUZA ${ }^{1}$, Jorge Fernando Fuentes ZAPATA ${ }^{1 \star}$, Ednardo Rodrigues FREITAS ${ }^{1}$, Manoel Alves SOUZA NETO ${ }^{2}$, Ana Lúcia Fernandes PEREIRA ${ }^{1}$, Tatiana Fontoura VIDAL ${ }^{1}$, Virgínia Kelly Gonçalves ABREU1', Elisabeth Mary Cunha da SILVA ${ }^{1}$

\begin{abstract}
Resumo
Foi estudado o efeito da inclusão de farelo de coco (FC) na ração de coelhos sobre o perfil de ácidos graxos, a relação de ácidos graxos poliinsaturados para saturados (P/S) e a composição centesimal da carne. O experimento utilizou 60 coelhos, cinco níveis de inclusão de FC na ração $(0,00 ; 6,25 ; 12,50 ; 18,75$; e 25,00\%) e doze repetições por tratamento. Os ácidos palmitoléico, esteárico e linolênico foram afetados linearmente pelo nível de FC na ração. A carne dos animais alimentados sem a adição de FC na ração apresentou maiores $(\mathrm{p}<0,05)$ valores de ácido palmítico em relação aos demais níveis de inclusão; maiores $(\mathrm{p}<0,05)$ níveis dos ácidos mirístico e esteárico e menor $(\mathrm{p}<0,05)$ nível de ácido palmitoléico quando comparada à carne proveniente da ração com 25,00\% de FC e menor ( $<0,05)$ nível de ácido linolênico em relação às carnes provenientes das rações contendo 18,75 e 25,00\% de FC. A relação P/S na carne não foi afetada $(\mathrm{p}>0,05)$ pelos tratamentos. O aumento do nível de FC na ração não afetou $(p>0,05)$ a composição centesimal, indicando que a inclusão desse subproduto na ração de coelhos é viável até $25,00 \%$.
\end{abstract}

Palavras-chave: perfil de ácidos graxos; composição proximal; qualidade nutricional.

\begin{abstract}
The objective of this work was to assess the effect of feeding rabbits diets containing coconut meal (CM) on meat proximal composition, the fatty acid profile, and the polyunsaturated to saturated (P/S) fatty acids ratio in the meat. The experiment utilized 60 rabbits fed diets containing five levels of $\mathrm{CM}(0.00,6.25,12.50,18.75$, and $25.00 \%)$ and 12 animals per treatment. Increasing levels of CM in the diet did not affect $(\mathrm{p}>0.05)$ meat centesimal composition. The levels of palmitoleic, stearic, and linolenic acids in the meat were linearly affected by dietary CM levels. When compared to the levels of fatty acids in the meat from the $0.00 \% \mathrm{CM}$ diet, the palmitic acid was lower $(\mathrm{p}<0.05)$ in the meat from all diets containing CM, the myristic and stearic acids were higher $(\mathrm{p}<0.05)$, and the palmitoleic acid was lower $(\mathrm{p}<0.05)$ in the meat from the diet containing $25.00 \%$ CM. The Linolenic acid level was lower $(\mathrm{p}<0.05)$ in meats from diets containing either 18.75 or $25.00 \% \mathrm{CM}$. The $\mathrm{P} / \mathrm{S}$ relation in the meat was not affected $(\mathrm{p}>0.05)$ by the levels of $\mathrm{CM}$ in the diets. This suggested that the inclusion of this by-product in the diets is feasible even at the $25.00 \%$ level.

Keywords: fatty acid profile; proximal composition; nutritional quality.
\end{abstract}

\section{Introdução}

A carne de coelho representa $1,2 \%$ do total de carne produzida na União Europeia, sendo que as regiões produtoras mais importantes são Itália, Espanha e França (FAO STAT, 2004). É amplamente difundida em quase toda a Europa, bem como em outros países como Ucrânia, China e Rússia, onde são consumidas mais de 100.000 toneladas de carne de coelho por ano (CASTELLINI et al., 1998). Quanto ao Brasil, em 2006, segundo dados do IBGE (2007), a produção de carne de coelho representava $0,02 \%$ do total de carne produzida. Segundo esta mesma fonte, os estados com maior plantel de coelhos são Rio Grande do Sul (34,00\%), São Paulo (20,05\%), Santa Catarina (11,55\%), Paraná $(11,19 \%)$ e Bahia $(7,55 \%)$.

A carne de coelho é considerada mais magra e mais saudável quando comparada às carnes bovina, ovina e suína.
Além disso, é altamente digerível, saborosa, baixa em calorias, gorduras e colesterol, sendo frequentemente recomendada pelos nutricionistas em regiões de maior produção dessa carne em detrimento das de ruminantes (HERNÁNDEZ et al., 2000). Contudo, esse tipo de alimento é considerado um produto de consumo limitado. Isso se deve, em parte, ao maior tempo de preparação por requerer habilidades culinárias e, também, às diferenças culturais entre os consumidores (CAVANI; PETRACCI, 2004).

$\mathrm{Na}$ produção animal, a alimentação representa a maior parcela dos custos totais, e por isso, a busca por alimentos alternativos que possam ser utilizados nas rações de coelhos tem sido motivo de pesquisas (FURLAN et al., 2003). No entanto, devem ser levados em consideração a localização

Recebido para publicação em 4/1/2008

Aceito para publicação em 17/7/2008 (003104)

1 Universidade Federal do Ceará - UFC, CP 12168, CEP 60021-190, Fortaleza-CE, Brasil, E-mail: zapata@ufc.br

${ }^{2}$ Embrapa Agroindústria Tropical, Rua Dra. Sara Mesquita, 2270, Planalto do Pici, CEP 60511-110, Fortaleza - CE, Brasil, E-mail: manoel@cnpat.embrapa.br

${ }^{*}$ A quem a correspondência deve ser enviada 
geográfica, a disponibilidade, o valor nutricional e os custos desses ingredientes.

No nordeste do Brasil, dentre os alimentos alternativos utilizados na alimentação animal, pode-se destacar o farelo ou torta de coco, subproduto obtido da extração do óleo que pode ser um substituto parcial do milho e do farelo de soja nas rações de monogástricos (BRAGA et al., 2005).

Segundo Creswell e Brooks (1971), a utilização do farelo de coco (FC) na ração de animais fornece um alimento com proteína de qualidade em áreas onde a disponibilidade de outras fontes de proteína é escassa, podendo contribuir assim para suprir a exigência proteica dos coelhos. O FC apresenta um teor de 20 a $25 \%$ de proteína bruta, nutriente com participação considerável no custo da alimentação (JÁCOME et al., 2002).

O FC, por seu alto conteúdo lipídico, também pode ser usado na ração como uma fonte energética (JÁCOME et al., 2002), no entanto apresenta a desvantagem da gordura do coco ser composta principalmente de ácidos graxos saturados (GROBAS; MATEOS, 1996), com destaque para os ácidos láurico (47\%) e mirístico (18\%). A incorporação de gordura animal ou vegetal na alimentação animal é atrativa do ponto de vista econômico, desde que elas sejam fontes de energia de baixo custo. Contudo, em animais monogástricos como o coelho, a quantidade e proporção dos ácidos graxos na carne e nos tecidos gordurosos mudam com a dieta (HERNÁNDEZ et al., 2000), podendo afetar de forma adversa a qualidade da carne deste animal.

Nas últimas décadas, a prevalência de doenças cardiovasculares no homem tem aumentado progressivamente, tornandose um grave problema de saúde pública, pois contribuem significativamente como grupo causal de mortalidade em todas as regiões brasileiras. Dentre os fatores de risco destas doenças, estão alguns hábitos relacionados ao estilo de vida, como dieta rica em energia, gorduras saturadas, colesterol e sal, bem como consumo de bebida alcoólica, tabagismo e sedentarismo (CASTRO et al., 2004).

De acordo com Castro et al. (2004), modificações na composição lipídica da dieta, notadamente no que se refere à quantidade e qualidade dos ácidos graxos ingeridos, podem promover alterações nos níveis séricos de colesterol, evidenciando o efeito da dieta sobre esse parâmetro sanguíneo. Assim, dietas ricas em ácidos graxos saturados e pobres em poli-insaturados aumentam as concentrações do colesterol sanguíneo. No entanto, diferentes classes de ácidos graxos saturados podem ter efeitos diferentes na concentração relativa das lipoproteínas plasmáticas (HU et al., 1999).

Desta forma, espera-se que a inclusão moderada de FC na ração de coelhos, apesar de conter ácidos graxos saturados e de modificar a composição lipídica da carne, possa constituir-se em uma alternativa viável, não afetando a qualidade nutricional dessa carne. Diante disto, o objetivo geral deste estudo foi a verificação do efeito da inclusão do farelo de coco na ração de coelhos sobre o perfil de ácidos graxos e a composição centesimal da carne.

\section{Material e métodos}

O experimento foi realizado no Centro de Ciências Agrárias da Universidade Federal do Ceará (UFC) em parceria com a Embrapa Agroindústria Tropical, sendo que: a formulação das rações, a alimentação e o abate dos coelhos foram realizados nos Setores de Cunicultura e Avicultura do Departamento de Zootecnia; as determinações de composição centesimal e a preparação dos extratos de metil ésteres de ácidos graxos foram executadas no Laboratório de Carnes e Pescado do Departamento de Tecnologia de Alimentos; e as análises cromatográficas dos metil ésteres de ácidos graxos foram realizadas no Laboratório de Análise de Alimentos da Embrapa Agroindústria Tropical.

Foi avaliada a carne de 60 coelhos (Nova Zelândia Branco $\times$ alifórnia) com 40 dias de idade, sendo 30 do sexo masculino e 30 do sexo feminino. Os coelhos foram alojados individualmente em gaiolas de arame galvanizado com bebedouros automáticos e comedouros semiautomáticos de chapa galvanizada, localizadas em galpão de alvenaria com pédireito de três metros e cobertura de telha de amianto.

O delineamento experimental foi inteiramente casualizado com cinco tratamentos e doze repetições por tratamento, sendo a unidade experimental constituída por um animal.

Os tratamentos consistiram de uma ração testemunha, sem farelo de coco (FC), e quatro rações contendo 6,25; 12,50; 18,75 ; e 25,00\% de FC, respectivamente. As rações experimentais foram formuladas com milho, farelo de soja e farelo de coco, incluindo-se cascas de arroz e de soja como fonte de fibras e areia lavada como inerte para manter em todas elas o mesmo nível nutricional, tornando-as isocalóricas, isoproteicas, isoaminoacídicas para metionina + lisina e lisina, isofibrosa para fibra em detergente ácido, isocálcicas, isofosfóricas e isosódicas (Tabela 1).

Durante o período experimental os animais receberam água ad libitum e ração, fornecida pela manhã e à tarde para evitar desperdícios.

O abate foi realizado com 40 dias de criação através de insensibilização por deslocamento cervical. Em seguida, os animais foram colocados em cones de aço inox para realizar o corte da artéria carótida e das veias jugulares para a sangria. Após esse procedimento, os animais foram pendurados em ganchos para que fosse realizada a retirada do rabo, da cabeça e das patas. Procedeu-se, então, à esfola seguida da evisceração.

As carcaças foram lavadas em água corrente para retirada do sangue remanescente e deixadas escorrer por 30 minutos. Em seguida, foram embaladas em sacos de polietileno, acondicionadas em caixas térmicas com gelo e transportadas para o Laboratório de Processamento de Carnes do Departamento de Tecnologia de Alimentos, onde foram transferidas para refrigerador $\left(2^{\circ} \mathrm{C}\right)$, sendo mantidas nessa temperatura por 24 horas.

No dia seguinte, as carcaças foram divididas ao meio, utilizando-se serra fita, ao longo da coluna vertebral. A porção do lombo (músculo Longissimus lumborus), situada na região das vértebras lombares, tanto da meia carcaça direita como da 
Tabela 1. Composição percentual e calculada das rações dos coelhos.

\begin{tabular}{|c|c|c|c|c|c|}
\hline \multirow[t]{2}{*}{ Ingredientes } & \multicolumn{5}{|c|}{ Níveis de FC (\%) } \\
\hline & 0,00 & 6,25 & 12,50 & 18,75 & 25,00 \\
\hline Milho & 28,351 & 22,573 & 19,051 & 16,849 & 15,990 \\
\hline Farelo de soja & 11,807 & 7,479 & 4,307 & 1,810 & 0,000 \\
\hline FC & 0,000 & 6,250 & 12,500 & 18,250 & 25,000 \\
\hline Farelo de trigo & 29,067 & 38,026 & 41,665 & 42,195 & 39,561 \\
\hline Casca de soja & 23,000 & 17,991 & 14,281 & 11,331 & 9,154 \\
\hline Casca de arroz & 4,439 & 4,439 & 4,439 & 4,439 & 4,439 \\
\hline Calcário & 1,293 & 1,147 & 1,541 & 1,544 & 1,480 \\
\hline Fosfato mono-bicálcico & 0,440 & 0,119 & 0,000 & 0,000 & 0,121 \\
\hline Vitamina - coelho ${ }^{1}$ & 0,300 & 0,300 & 0,300 & 0,300 & 0,300 \\
\hline Mineral - coelho ${ }^{2}$ & 0,200 & 0,200 & 0,200 & 0,200 & 0,200 \\
\hline DL - Metionina & 0,156 & 0,155 & 0,156 & 0,160 & 0,166 \\
\hline $\mathrm{L}$ - Lisina $\mathrm{HCl}$ & 0,251 & 0,307 & 0,355 & 0,400 & 0,440 \\
\hline Antioxidante - BHT & 0,020 & 0,020 & 0,020 & 0,020 & 0,020 \\
\hline Sal Comum & 0,677 & 0,670 & 0,664 & 0,659 & 0,654 \\
\hline Inerte & 0,000 & 0,000 & 0,520 & 1,343 & 2,476 \\
\hline Total & 100,000 & 100,000 & 100,000 & 100,000 & 100,000 \\
\hline \multicolumn{6}{|c|}{ Composição calculada } \\
\hline Energia digestível (Mcal/kg) & 2,550 & 2,550 & 2,550 & 2,550 & 2,550 \\
\hline Proteína bruta (\%) & 16,000 & 16,000 & 16,000 & 16,000 & 16,000 \\
\hline Gordura (\%) & 2,615 & 3,858 & 5,043 & 6,193 & 7,308 \\
\hline Fibra bruta (\%) & 13,437 & 13,110 & 12,861 & 12,657 & 12,498 \\
\hline Fibra em detergente ácido (\%) & 18,550 & 18,550 & 18,550 & 18,550 & 18,550 \\
\hline Fibra em detergente neutro (\%) & 33,175 & 36,329 & 38,505 & 40,110 & 41,133 \\
\hline Cálcio (\%) & 0,800 & 0,800 & 0,800 & 0,800 & 0,800 \\
\hline Fósforo total (\%) & 0,500 & 0,500 & 0,500 & 0,500 & 0,500 \\
\hline Sódio (\%) & 0,300 & 0,300 & 0,300 & 0,300 & 0,300 \\
\hline Lisina total (\%) & 0,800 & 0,800 & 0,800 & 0,800 & 0,800 \\
\hline Metionina + lisina total (\%) & 0,600 & 0,600 & 0,600 & 0,600 & 0,600 \\
\hline
\end{tabular}

${ }^{1}$ Suplemento vitamínico: vitamina A 1.400 .000 UI; vitamina D3 250.000 UI; vitamina E 7.000 mg; vitamina k3 400 mg; vitamina B1 500 mg; vitamina B2 1.000 mg; niacina 6.000 mg; vitamina B6 400 mg; pantotenato de cálcio 2.000 mg; ácido fólico 100 mg; vitamina B12 2.500 mcg; ${ }^{2}$ Suplemento mineral: colina 25 g; cobalto 100 mg; cobre 2.400 mg; ferro 16.000 mg; iodo $200 \mathrm{mg}$; manganês $12.000 \mathrm{mg}$; selênio $40 \mathrm{mg}$; zinco $10.000 \mathrm{mg}$; antioxidante $40 \mathrm{~g}$; e coccidiostático $6,6 \mathrm{~g}$.

esquerda, foi utilizada para a análise do perfil de ácidos graxos. Essa porção de carne foi homogeneizada em processador de alimentos e, em seguida, da massa obtida, foram pesados aproximadamente $10 \mathrm{~g}$ que foram espalhados sobre a superfície de placas de Petri para posterior liofilização. Após esse processo, o material liofilizado foi protegido da luz com papel alumínio e embalado em sacos de nylon-polietileno a vácuo e armazenados em temperatura ambiente até a preparação dos extratos de metil ésteres.

A preparação dos extratos foi realizada de acordo com Wang et al. (2000). As análises cromatográficas foram realizadas em cromatógrafo gasoso (VARIAN CP 3380), equipado com um detector de ionização de chama (DIC). As condições analíticas utilizadas foram adaptadas a partir da metodologia descrita por Barreto (2005): coluna capilar SP ${ }^{\mathrm{TM}}$ - 2560, (Suppelco, Bellafonte, PA), de $100 \mathrm{~m}$ de comprimento, diâmetro interno de $0,25 \mathrm{~mm}$ e espessura do filme de $0,2 \mu \mathrm{m}$; hidrogênio como gás de arraste com fluxo de $1,5 \mathrm{~mL} /$ minuto; temperatura de $250{ }^{\circ} \mathrm{C}$ para injetor e detector; programação de temperatura da coluna: $160^{\circ} \mathrm{C}$ (inicial) a $240^{\circ} \mathrm{C}$, com aumento numa razão de $3,5{ }^{\circ} \mathrm{C} /$ minuto, permanecendo a $240{ }^{\circ} \mathrm{C}$ por 8 minutos.
Foram realizadas injeções, em duplicata, de $1 \mu \mathrm{L}$ da amostra no modo splitless. Os metil ésteres dos ácidos graxos mais abundantes foram identificados por comparação com os tempos de retenção dos padrões de ésteres metílicos (Supelco) dos ácidos graxos C-8 a C-22. Estes padrões estavam compostos pelos ácidos caprílico (C8:0), cáprico (C10:0), láurico (C12:0), mirístico (C14:0), palmítico (C16:0), palmitoléico (C16:1), esteárico (C18:0), oleico (C18:1), linoleico (C18:2), linolênico (C18:3), araquídico (C20:0), eicosenoico (C20:1), behênico (C22:0) e erúcico (C22:1).

A quantificação dos ácidos graxos presentes na carne de coelho foi calculada mediante a porcentagem da área de cada pico correspondente ao ácido graxo identificado pelos padrões.

A partir dos valores percentuais dos ácidos graxos foi calculada a relação de ácidos graxos poli-insaturados/saturados. Para tal, os ácidos graxos poli-insaturados utilizados foram o linoleico e o linolênico e os ácidos graxos saturados foram: mirístico, palmítico, esteárico, araquídico e behênico. 
A carne proveniente das sobrecoxas direitas foi utilizada para a análise de composição centesimal. Os teores de umidade, proteína, gordura e cinzas das carnes foram determinados segundo a AOAC (1990).

Todas as amostras foram embaladas individualmente em sacos de nylon-polietileno, devidamente codificadas, seladas a vácuo, congeladas $\left(-30^{\circ} \mathrm{C}\right)$ e armazenadas $\left(-20^{\circ} \mathrm{C}\right)$ para posterior análise.

A análise estatística foi realizada utilizando o programa estatístico Statistical Analysis System (2000). O modelo estatístico utilizado para a análise de variância foi (Equação 1):

$\mathrm{Yijk}=(\mu+\mathrm{Ni}+\mathrm{Sj}+\mathrm{Nsij}+\mathrm{eijk})$

em que, $\mu=$ média geral, $\mathrm{Ni}=$ efeito do nível de inclusão do farelo de coco ( $\mathrm{i}=0 ; 6,25 \% ; 12,50 \% ; 18,75 \%$; e $25,00 \%), \mathrm{Sj}=$ efeito do sexo ( $\mathrm{j}$ = macho e fêmea), $\mathrm{Nsij}=$ efeito do nível de inclusão i sobre o sexo j e eijk = efeito do erro. Como o efeito do sexo não foi significativo este foi retirado do modelo.

Os graus de liberdade referentes aos níveis de inclusão do farelo de coco, excluindo-se a ração testemunha (nível zero de inclusão de farelo de coco), foram desdobrados em polinômios e, para estabelecer o melhor nível de inclusão, foi utilizado o modelo quadrático.

Para a comparação dos resultados obtidos com cada um dos níveis de inclusão em relação à ração testemunha, foi utilizado o teste de Dunett (5\%).

\section{Resultados e discussão}

De acordo com a análise de regressão, não foram observados efeitos significativos $(\mathrm{p}>0,05)$ entre o nível de FC na ração e os ácidos graxos mirístico, palmítico, oleico, linoleico e araquídico da carne. Entretanto, o nível de FC alterou significativamente $(\mathrm{p}<0,05)$ os ácidos graxos: palmitoléico, esteárico, linolênico e erúcico, sendo observados efeitos lineares regidos pelas Equações 2, 3, 4 e 7, respectivamente (Tabela 2).
Os ácidos graxos eicosenoico e behênico também sofreram uma alteração significativa $(\mathrm{p}<0,05)$ com o nível de FC como pode ser observado pelo efeito quadrático segundo as Equações 5 e 6, respectivamente (Tabela 2). Com 15\% de inclusão de FC, este efeito foi máximo no eicosenoico e com 10\% de FC, foi mínimo no behênico.

Comparando-se ao tratamento controle ( $0,00 \%$ de FC), os níveis dos ácidos mirístico, esteárico e behênico foram mais altos $(\mathrm{p}<0,05)$ e o do ácido palmitoléico mais baixo $(\mathrm{p}<0,05)$ quando o nível de inclusão era de $25,00 \%$. O nível do ácido palmítico foi menor $(\mathrm{p}<0,05)$ a partir do nível de inclusão de $6,25 \%$ e teores dos ácidos linolênico e erúcico foram menores $(\mathrm{p}<0,05)$ a partir do nível de inclusão de $18,75 \%$. Os ácidos oleico, linoleico, araquídico e eicosenoico, por sua vez, não variaram significativamente $(\mathrm{p}>0,05)$ com a inclusão do FC na ração.

Resultados semelhantes ao presente estudo foram obtidos por Oliver et al. (1997) ao incluírem gordura animal na dieta de coelhos. Esses autores observaram uma redução nos ácidos palmítico, palmitoléico e linolênico e um aumento no ácido esteárico da gordura perirenal destes animais.

O ácido palmítico é um dos responsáveis pelo aumento do colesterol total e LDL colesterol em humanos (SCHAEFER, 1997). Desta forma, a redução deste ácido na carne de coelho com a inclusão do FC na ração constitui uma vantagem para o consumidor, do ponto de vista nutricional.

Cobos et al. (1993), por sua vez, estudaram a influência de dietas enriquecidas com sebo bovino e óleos de soja e de girassol na carne de coelhos. Os resultados encontrados por estes autores, para os animais alimentados com dietas contendo sebo bovino, estão de acordo com os obtidos no presente estudo, visto que houve redução nos ácidos palmítico, palmitoléico, linoleico e linolênico e aumento no ácido esteárico.

O ácido esteárico, apesar de ser saturado e a inclusão do FC ter contribuído para o aumento de seus níveis no presente estudo,

Tabela 2. Composição dos principais ácidos graxos (\%) da carne de coelhos alimentados com ração contendo diferentes níveis de farelo de coco (FC).

\begin{tabular}{|c|c|c|c|c|c|c|c|}
\hline \multirow[t]{2}{*}{ Ácidos graxos (\%) } & \multicolumn{7}{|c|}{ Níveis de FC (\%) } \\
\hline & 0,00 & 6,25 & 12,50 & 18,75 & 25,00 & Média & CV (\%) \\
\hline Mirístico (C14:0) & 1,42 & 1,98 & 2,47 & 2,56 & $3,19^{*}$ & 2,32 & 41,12 \\
\hline Palmítico (C16:0) & 21,05 & $19,07^{\star}$ & $17,84^{\star}$ & $18,96^{*}$ & $18,90^{*}$ & 19,16 & 6,84 \\
\hline Palmitoléico $^{1}(\mathrm{C} 16: 1)$ & 1,69 & 1,71 & 1,40 & 1,20 & $0,67^{\star}$ & 1,34 & 42,35 \\
\hline Esteárico² $^{2}$ C18:0) & 7,57 & 7,89 & 8,19 & 8,63 & $9,43^{*}$ & 8,34 & 9,51 \\
\hline Oléico (C18:1) & 17,85 & 16,35 & 18,14 & 16,68 & 16,93 & 17,19 & 11,00 \\
\hline Linoléico (C18:2) & 20,95 & 19,91 & 20,31 & 20,80 & 17,74 & 19,94 & 20,37 \\
\hline Linolênico $^{3}$ (C18:3) & 0,65 & 0,64 & 0,61 & $0,41^{*}$ & $0,35^{\star}$ & 0,53 & 23,22 \\
\hline Araquídico (C20:0) & 0,13 & 0,15 & 0,17 & 0,20 & 0,15 & 0,16 & 41,34 \\
\hline Eicosenóico $^{4}(\mathrm{C} 20: 1)$ & 0,17 & 0,19 & 0,25 & 0,19 & 0,07 & 0,17 & 43,87 \\
\hline Behênico $^{5}$ (C22:0) & 0,17 & 0,15 & 0,16 & 0,22 & $0,43^{*}$ & 0,23 & 33,05 \\
\hline Erúcico $^{6}(\mathrm{C} 22: 1)$ & 0,53 & 0,36 & 0,38 & $0,15^{*}$ & $0,07^{*}$ & 0,30 & 67,43 \\
\hline
\end{tabular}

${ }^{1}$ Efeito linear $\left(\mathrm{y}=2,08-0,05 \mathrm{x} ; \mathrm{R}^{2}=40,39\right)$, onde $\mathrm{y}=$ quantidade de ácido palmitoléico; $\mathrm{x}=$ nível de FC na ração; $\mathrm{R}^{2}=$ coeficiente de determinação; ${ }^{2}$ efeito linear ( $\mathrm{y}=7,27+0,08 \mathrm{x}$; $\left.\mathrm{R}^{2}=40,50\right) ;{ }^{3}$ efeito linear $\left(\mathrm{y}=0,77-0,017 \mathrm{x} ; \mathrm{R}^{2}=0,49\right) ;{ }^{4}$ efeito quadrático $\left(\mathrm{y}=0,07+0,03 \mathrm{x}-0,001 \mathrm{x}^{2} ; \mathrm{R}^{2}=0,43\right) ;{ }^{5} \mathrm{efeito}$ quadrático $\left(\mathrm{y}=0,25-0,02 \mathrm{x}+0,001 \mathrm{x}^{2} ; \mathrm{R}^{2}=0,71\right) ;{ }^{6}$ efeito linear $\left(\mathrm{y}=0,52-0,018 \mathrm{x} ; \mathrm{R}^{2}=0,30\right) ; \mathrm{n}=6$; $\mathrm{e}^{\star}$ médias diferentes em relação ao nível zero de inclusão, pelo Teste de Dunnett $(\mathrm{p}<0,05)$. 
é considerado neutro em relação às concentrações plasmáticas de colesterol, uma vez que, dentro do organismo humano, é rapidamente convertido a ácido oleico, o qual apresenta efeitos hipocolesterolêmicos (CASTRO et al., 2004).

Gondret et al. (1998), comparando o efeito de dietas enriquecidas com óleos vegetais de girassol, de palma e de coco, observaram que os lipídios da carne de coelhos apresentavam menor conteúdo do ácido graxo eicosenoico quando alimentados com óleo de coco.

Resultados semelhantes aos encontrados no presente estudo foram obtidos por Crespo e Esteve-Garcia (2002) ao avaliarem o perfil de ácidos graxos em fígados de frangos alimentados com dietas com inclusão de $10 \%$ de sebo bovino. Esses autores observaram um aumento do ácido mirístico e um decréscimo nos ácidos palmitoléico e linolênico.

Dentre os ácidos graxos saturados, o mirístico parece ser o principal causador da elevação dos níveis do LDL colesterol em humanos, quando comparado com o láurico e o palmítico (KRIS-ETHERTON; YU, 1997). Embora tenha ocorrido um aumento significativo deste ácido com a inclusão do FC, este aumento não afetou a relação $\mathrm{P} / \mathrm{S}$.

Alterações no perfil de ácidos graxos da carne de suínos alimentados com dieta contendo elevados níveis de gordura monoinsaturada foram analisadas por Miller et al. (1990), os quais encontraram uma redução nos ácidos palmítico, palmitoléico e oleico. Alterações semelhantes têm sido observadas na carne de ruminantes. Scheeder et al. (2001) avaliaram a composição de ácidos graxos de empanados de carne bovina de animais alimentados com dietas contendo 3\% de óleo de coco. Os autores observaram maiores níveis dos ácidos mirístico e araquídico e um menor nível do ácido oleico nessa carne quando comparados aos da carne do tratamento controle.

Segundo Hafs e Zimbelman (1994), os ácidos graxos de cadeia curta (8 a 12 carbonos) da dieta, como o ácido láurico (majoritário no óleo de coco), não são quantitativamente depositados nos tecidos devido a diferenças na taxa de hidrólise e na absorção desses lipídios. Isso poderia explicar o fato do ácido láurico não ter sido detectado neste estudo.

Os ácidos behênico e erúcico não são comumente relatados na literatura como ácidos graxos importantes na carne de coelho. No entanto, neste estudo eles apresentaram variações com os níveis de inclusão de FC.

Embora o ácido behênico tenha aumentado com os níveis de inclusão de FC, ele é considerado neutro, não afetando as concentrações de colesterol plasmático. Sua neutralidade é consequência da baixa absorção e baixa biodisponibilidade, quando comparado com outros ácidos graxos, como também do longo comprimento da sua cadeia hidrocarbonada (CATER; DENKE, 2001).

Já o ácido erúcico, apesar de insaturado, pode contrabalancear os efeitos benéficos do ácido linolênico, por aumentar as concentrações séricas do LDL colesterol e dos triglicerídios (RASTOGI et al., 2004). Portanto, a redução do ácido erúcico observada na carne de coelho com a inclusão de FC pode trazer benefícios à saúde do consumidor.
Os teores de gorduras poli-insaturadas $(\mathrm{P})$, saturadas $(\mathrm{S})$ e os valores da relação $\mathrm{P} / \mathrm{S}$ são apresentados na Tabela 3. De acordo com a análise de regressão, os ácidos graxos saturados sofreram um efeito linear regido pela Equação 2 com coeficiente de regressão $R^{2}=24,17$.

$y=27,76+0,15 x$

Com relação ao tratamento controle ( $0 \%$ de FC) observouse que o nível de FC não alterou significativamente $(\mathrm{p}>0,05)$ a relação poli-insaturados/saturados.

Gondret et al. (1998), comparando o efeito da dieta enriquecida com óleos vegetais de girassol, de palma e de coco, observaram uma maior relação $\mathrm{P} / \mathrm{S}$ na carne de coelhos alimentados com óleo de girassol $(1,3)$ quando comparada àqueles alimentados com óleo de palma $(0,7)$ e óleo de coco $(0,6)$.

Teye et al. (2006), estudando a influência de óleos vegetais adicionados na dieta sobre a composição lipídica da carne de suínos, observaram que a relação entre poli-insaturados e saturados era menor na carne dos animais alimentados com óleo de palma, o qual é rico em ácidos graxos saturados, em relação àqueles alimentados com óleo de soja.

Mitchaothai et al. (2007), ao avaliar o efeito da dieta com inclusão de óleo de girassol e sebo bovino sobre a composição lipídica da carne suína, observaram uma menor relação P/S na carne dos animais alimentados com sebo bovino.

A qualidade das gorduras ingeridas pelo consumidor é definida pela relação entre os teores de gorduras poli-insaturadas e saturadas, sendo que quanto maior esta relação (maior a quantidade de poli-insaturadas), mais aconselhável é o seu consumo. Além disso, as gorduras mono e poli-insaturadas não aumentam o nível de colesterol no sangue.

Vale ressaltar que os valores da razão P/S (Tabela 3) são considerados altos para a carne de coelho quando comparados com os de outras carnes. Enser et al. (1996), avaliando a composição lipídica das carnes bovina, ovina e suína, encontraram valores de $\mathrm{P} / \mathrm{S}$ de $0,11,0,15$ e 0,58, respectivamente.

Tabela 3. Relação de ácidos graxos poliinsaturados/saturados (P/S) da carne de coelhos alimentados com ração contendo diferentes níveis de farelo de coco (FC).

\begin{tabular}{cccl}
\hline Níveis de FC (\%) & Poliinsaturados & Saturados $^{1}$ & P/S \\
\hline 0,00 & 21,60 & 30,33 & 0,71 \\
6,25 & 20,55 & 29,24 & 0,71 \\
12,50 & 20,92 & 28,83 & 0,73 \\
18,75 & 21,21 & 30,56 & 0,70 \\
25,00 & 21,59 & 31,84 & 0,68 \\
Média & 21,15 & 30,10 & 0,70 \\
CV\% & 5,95 & 6,02 & 8,70 \\
\hline
\end{tabular}

${ }^{1}$ Efeito linear $\left(\mathrm{y}=27,76+0,15 \mathrm{x} ; \mathrm{R}^{2}=0,24\right)$ onde, $\mathrm{y}=$ quantidade dos ácidos saturados; $\mathrm{x}$ = nível de FC na ração; $\mathrm{R}^{2}$ = coeficiente de determinação; $\mathrm{n}=6$; P/S: relação de ácidos graxos poliinsaturados e saturados; e *médias diferentes em relação ao nível zero de inclusão, pelo Teste de Dunnett $(\mathrm{p}<0,05)$. 
Tabela 4. Percentuais de umidade, proteína, gordura e cinzas em carne de coelhos alimentados com ração contendo diferentes níveis de farelo de $\operatorname{coco}(\mathrm{FC})$.

\begin{tabular}{ccccc}
\hline Níveis de FC (\%) & \multicolumn{3}{c}{ Componentes } \\
\cline { 2 - 5 } & Umidade (\%) & Proteína (\%) & Gordura (\%) & Cinzas (\%) \\
\hline 0,00 & 77,33 & 19,63 & 2,03 & 2,05 \\
1,13 \\
6,25 & 77,65 & 18,93 & 2,36 & 1,06 \\
12,50 & 77,35 & 19,30 & 2,83 & 1,07 \\
18,75 & 76,35 & 19,78 & 2,40 & 1,13 \\
25,00 & 77,46 & 19,22 & 2,33 & 1,11 \\
Média & 77,23 & 19,37 & 28,29 & 5,14 \\
CV\% & 1,19 & 3,73 & & \\
\hline
\end{tabular}

$\mathrm{n}=6 ; \mathrm{e}^{\star}$ médias diferentes em relação ao nível zero de inclusão, pelo Teste de Dunnett $(\mathrm{p}<0,05)$.

O Departamento de Saúde dos Estados Unidos citado por Wood et al. (2003) menciona que a relação P/S inferior a 0,4 constitui uma dieta pouco saudável, sendo que o aumento desta razão está diretamente associado com uma redução no risco de doenças cardiovasculares (TANASESCU et al., 2004). Assim, a relação $\mathrm{P} / \mathrm{S}$ encontrada neste estudo indica que a carne de coelhos alimentados com FC encontra-se dentro dos limites aceitáveis.

Neste experimento, o aumento dos níveis de FC na ração não afetou significativamente $(\mathrm{p}>0,05)$ a composição centesimal da carne (Tabela 4). Cobos et al. (1993), ao estudarem a influência de dietas enriquecidas com sebo bovino e óleos de soja e girassol, não encontraram diferenças na composição química da carne de coelhos.

Fernández e Fraga (1996) concluíram que a adição de 3\% de sebo bovino e óleo de soja na dieta de coelhos, não afeta significativamente o conteúdo lipídico da carne.

Portanto, os baixos níveis de gordura, característicos da carne de coelho não foram alterados pela inclusão do FC, mantendo assim a sua qualidade nutricional.

\section{Conclusões}

Os diferentes níveis de FC usados neste estudo na ração de coelhos aumentam os ácidos mirístico (C14:0) e esteárico (C18:0), enquanto diminuem os ácidos palmítico (C16:0), palmitoléico (C16:1) e linolênico (C18:3) na carne.

A inclusão de $\mathrm{FC}$ em níveis de até $25,00 \%$ na ração de coelhos modifica o perfil de ácidos graxos da carne. No entanto, a relação de ácidos graxos poli-insaturados/saturados não é alterada, viabilizando o uso desse ingrediente na alimentação desses animais.

A composição centesimal não é alterada pelos níveis de FC utilizados na ração.

\section{Agradecimentos}

À Coordenação de Aperfeiçoamento de Pessoal de Nível Superior - CAPES pela bolsa de mestrado concedida à primeira autora. Aos funcionários do Laboratório de Carnes DTA/UFC, Luís Alves Bitu e Rozelúcia Barrôzo, pela ajuda nas determinações de composição centesimal.

\section{Referências bibliográficas}

ASSOCIATION OF OFFICIAL ANALYTICAL CHEMISTS - AOAC. Official methods of analysis. $15 \mathrm{ed}$. Virginia, 1990. $1214 \mathrm{p}$.

BARRETO, S. C. S. Qualidade e composição lipídica de ovos de poedeiras comerciais alimentadas com farelo de coco na ração. Fortaleza, 2005. 91 f. Dissertação (Mestrado em Tecnologia de Alimentos) - Universidade Federal do Ceará.

BRAGA, C. V. P. et al. Efeito da Inclusão do Farelo de Coco em Rações para Poedeiras Comerciais. Revista Brasileira de Zootecnia, v. 34, n. 1, p. 76-80, 2005.

CASTELLINI, C. et al. Effect of dietary vitamin E on the oxidative stability of raw and cooked rabbit meat. Meat Science, v. 50, n. 2, p. 153-161, 1998.

CASTRO, L. C. V. et al. Nutrição e doenças cardiovasculares: os marcadores de risco em adultos. Revista de Nutrição, v. 17, n. 3, p. 369-377, 2004.

CATER, N. B.; DENKE, M. A. Behenic acid is a cholesterol-raising saturated fatty acid in humans. American Journal of Clinical Nutrition, v. 73, n. 1, p. 41-44, 2001

CAVANI, C.; PETRACCI, M. Rabbit meat processing and traceability. In: WORLD RABBIT CONGRESS, 8, 2004, 7-10 September, Puebla, México. Proceedings... p. 1318-1336.

COBOS, A. et al. Effect of fat-enriched diets on rabbit meat fatty acid composition. Journal of the Science of Food and Agriculture, v. 62 , n. 1, p. 83-88, 1993.

CRESPO, N.; ESTEVE-GARCIA, E. Dietary linseed oil produces lower abdominal fat deposition but higher de novo fatty acid synthesis in broiler chickens. Poultry Science, v. 81, n. 10, p. 1555-1562, 2002.

CRESWELL, D. C.; BROOKS, C. C. Effect of coconut meal on coturnix quail and coconut meal and coconut oil on performance carcass measurements and fat composition in swine. Journal of Animal Science, v. 33, n. 2, p. 370-375, 1971.

ENSER, M. et al. Fatty acid content and composition of English beef, lamb and pork at retail. Meat Science, v. 42, n. 4, p. 443-456, 1996.

FERNÁNDEZ, C.; FRAGA, M. J. The effect of dietary fat inclusion on growth, carcass characteristics, and chemial composition of rabbits. Journal of Animal Science, v. 74, n. 9, p. 2088-2094, 1996.

FOOD AND AGRICULTURE ORGANIZATION OF THE UNITED NATIONS - FAOSTAT. Agriculture 2004. Disponível em: $<$ http:// faostat.fao.org>. Acesso em: 6 Abril 2001. 
FURLAN, A. C. et al. Valor nutritivo e desempenho de coelhos em crescimento alimentados com rações contendo milho extrusado. Revista Brasileira de Zootecnia, v. 32, n. 5, p. 1157-1165, 2003.

GONDRET, F. et al. Effects of dietary fatty acids on lipogenesis and lipid traits in muscle adipose tissue and liver of growing rabbits. Animal Science, v. 66, part 2, p. 483-489, 1998.

GROBAS, S.; MATEOS, G. G. Influencia de la nutricion sobre la composicion nutricional del huevo. In: CURSO DE ESPECIALIZACIÓN FEDNA, 12, 1996, Barcelona. Barcelona: FEDNA, 1996. p. 219-244. Curso de especialización

HAFS, H. D.; ZIMBELMAN, R. G. Low-Fat Meats: design Strategies and human Implications. London: Academic Press, 1994. 328 p.

HERNÁNDEZ, P. et al. Relationships between meat quality measurements in rabbits fed with three diets of different fat type and content. Meat Science, v. 55, n. 4, p. 379-384, 2000.

HU, F. B. et al. Dietary saturated fats and their food sources in relation to the risk of coronary heart disease in women. American Journal of Clinical Nutrition, v. 70, n. 6, p. 1001-1008, 1999.

INSTITUTO BRASILEIRO DE GEOGRAFIA E ESTATÍSTICA IBGE. 2007. Disponível em: < http://www.ibge.gov.br >. Acesso em: 06 Abril 2008.

JÁCOME, I. M. T. D. et al. Efeitos da inclusão do farelo de coco nas rações de frangos de corte sobre o desempenho e rendimento da carcaça. Acta Scientiarum, v. 24, n. 4, p. 1015-1019, 2002.

KRIS-ETHERTON, P. M.; YU, S. Individual fatty acid effects on plasma lipids and lipoproteins: human studies. American Journal of Clinical Nutrition, v. 65, n. 5, p. 1628S-1644S, 1997.

MILLER, M. F. et al. Determination of the alteration in falty acid profiles, sensory characteristics and carcass traits of swine fed elevated levels of monounsaturated fats in the diet. Journal of Animal Science, v. 68, n. 6, p. 1624-1631, 1990.
MITCHAOTHAI, J. et al. Effect of dietary fat type on meat quality and fatty acid composition of various tissues in growing-finish swine. Meat Science, v. 76, n. 1, p. 95-101, 2007.

OLIVER, M. A. et al. The effect of fat-enriched diets on the perirenal fat quality and sensory characteristics of meat from rabbits. Meat Science, v. 47, n. 1/2, p. 95-103, 1997.

RASTOGI, T. et al. Diet and risk of ischemic heart disease in India. American Journal of Clinical Nutrition, v. 79, n. 4, p. 582-592, 2004.

SCHAEFER, E. J. Effect of dietray fatty acids on lipoproteins and cardiovascular disease risk: summary. American Journal of Clinical Nutrition, v. 65, n. 5, p. 1655-1656, 1997.

SCHEEDER, M. R. L. et al. Fatty acid composition, cooking loss and texture of beef patties from meat of bulls fed different fats. Meat Science, v. 58, n. 3, p. 321-328, 2001

STATISTICAL ANALYSIS SYSTEM. SAS/STAT: User's guide. Version 6. 12 ed. Cary: SAS Institute Inc., 2000.

TANASESCU, M. et al. Dietary fat and cholesterol and the risk of cardiovascular disease among women with type 2 diabetes. American Journal of Clinical Nutrition, v. 79, n. 6, p. 999-1005, 2004.

TEYE, G. A. et al. Influence of dietary oils and protein level on pork quality. 1. Effects on muscle fatty acid composition, carcass, meat and eating quality. Meat Science, v. 73, n. 1, p. 157-165, 2006.

WANG, Y. et al. Fatty acid determination in chicken egg yolk: a comparison of different methods. Poultry Science, v. 79, n. 8, p. 1168-1171, 2000.

WOOD, J. D. et al. Effects of fatty acids on meat quality: a review. Meat Science, v. 66, n. 1, p. 21-32, 2003. 